\title{
ROLES OF DNA REPAIR METHYLTRANSFERASE IN MUTAGENESIS AND CARCINOGENESIS
}

\author{
Mutsuo SeKIGUCHI ${ }^{1, *}$ and Kunihiko SAKUMI ${ }^{2}$ \\ ${ }^{1}$ Fukuoka Dental College, Fukuoka 814-01, Japan \\ ${ }^{2}$ Medical Institute of Bioregulation, Kyushu University, Fukuoka 812-82, Japan
}

Summary Alkylation of DNA at the $O^{6}$-position of guanine is one of the most critical events leading to induction of mutation as well as cancer. An enzyme, $O^{6}$-methylguanine-DNA methyltransferase, is present in various organisms, from bacteria to human cells, and appears to be responsible for preventing the occurrence of such mutations. The enzyme transfers methyl groups from $O^{6}$-methylguanine and other methylated moieties of the DNA to its own molecule, thereby repairing DNA lesions in a single-step reaction. To elucidate the role of methyltransferase in preventing cancer, animal models with altered levels of enzyme activity were generated. Transgenic mice carrying extra copies of the foreign methyltransferase gene showed a decreased susceptibility to alkylating carcinogens, with regard to tumor formation. By means of gene targeting, mouse lines defective in both alleles of the methyltransferase gene were established. Administration of methylnitrosourea to these gene-targeted mice led to early death while normal mice treated in the same manner showed no untoward effects. Numerous tumors were formed in the gene-defective mice exposed to a low dose of methylnitrosourea, while none or only few tumors were induced in the methyltransferase-proficient mice. It seems apparent that the DNA repair methyltransferase plays an important role in lowering a risk of occurrence of cancer in organisms. Key Words mutation, tumor, DNA damage, DNA repair, alkylating agent

\section{Introduction}

Exposure of cells to alkylating agents produces varius alkylated adducts in DNA. Among many of the alkylated bases formed, $O^{6}$-methylguanine appears to be a major pre-mutagenic lesion in organisms (Loveless, 1969; Strauss et al., 1975). During DNA replication, $O^{6}$-methylguanine pairs with cytosine as well as thymine

*To whom correspondence should be addressed. 
and, as a result, the guanine-cytosine pair can be converted to the adenine-thymine pair (Coulondre and Miller, 1977). Such mutations are frequent in DNA sequences of organisms exposed to relatively low levels of alkylating agents (Ito et al., 1994), and it has been demonstrated that mammary tumors of rats, as induced by injection of methylnitrosourea (MNU), carry this type of mutation in the Ha-ras-1 gene (Sukumar et al., 1983).

To counteract such effects, organisms possess a mechanism to repair $O^{6}$-methylguanine in DNA. An enzyme, $O^{6}$-methylguanine-DNA methyltransferase, is present in various organisms, and appears to be responsible for preventing the occurrence of such mutations (Demple et al., 1982; Sekiguchi et al., 1996). The enzyme transfers methyl groups from $O^{6}$-methylguanine and other methylated moieties of the DNA to its own molecule, thereby repairing DNA lesions in a single-step reaction. Since this reaction irreversibly inactivates the enzyme, the capacity for $O^{6}$-methylguanine adduct repair depends on the number of active enzyme molecules per cell (Ishibashi et al., 1994a, b).

Cellular contents of methyltransferase protein vary with tissues, and it was pointed out that more tumors are formed in tissues with less methyltransferase activity, in alkylnitrosourea-administered animals (Kleihues and Margison, 1974; Goth and Rajewsky, 1974; Gerson et al., 1986). Some human tumor-derived cell lines are hypersensitive to alkylating agents, and these cell lines, termed $\mathrm{Mer}^{-}$or $\mathrm{Mex}^{-}$, have little or no methyltransferase activity (Day et al., 1980; Sklar and Strauss, 1981; Yarosh et al., 1983). It was suspected that this methyltransferase deficiency might possibly explain the frequent occurrence of tumors, in certain cases, even though methyltransferase deficiency is in most cases the consequence of cellular transformation.

To elucidate the roles of methyltransferase in preventing occurrence of cancer, appropriate animal models with altered levels of the enzyme activity are needed. We and several other investigators generated transgenic mice with elevated levels of methyltransferase activity and found that such animals are more resistant to tumor induction by alkylating agents, as compared with normal mice (Nakatsuru et al., 1993; Dumenco et al., 1993; Zaidi et al., 1995). We also obtained methyltransferase-deficient mice by gene targeting and demonstrated that such mice are extremely hypersensitive to alkylating carcinogens (Tsuzuki et al., 1996; Sakumi et al., 1997; Iwakuma et al., 1997). We summarize here an update on understanding of roles of methyltransferase in mutagenesis and carcinogenesis.

\section{Structure and Function of Methyltransferase}

Many organisms, from bacteria to humans, carry the enzyme, $O^{6}$-methylguanine-DNA methyltransferase. The structure and function of methyltransferase have been studied extensively in Escherichia coli (Nakabeppu et al., 1985; Demple et al., 1985; Margison et al., 1985; LeMotte and Walker, 1985; Wilkinson et al., 1989). We will first review briefly characteristics of the enzyme from this bacterium. 
E. coli possesses two types of methyltransferase, a 39-kDa Ada protein and a $19-\mathrm{kDa}$ Ogt protein, coded by $a d a$ and ogt genes, respectively. The Ada protein carries two distinct methyltransferase activities, one to transfer a methyl group from methylphosphotriester and the other to transfer a methyl group from either $O^{6}$-methylguanine or $O^{4}$-methylthymine of methylated DNA. These two activities reside on $\mathrm{N}$-terminal and $\mathrm{C}$-terminal halves of the Ada protein, and the Ogt protein carries only the region corresponding to the latter (Fig. 1). Although methylation of the phosphate backbone of DNA has no major biological effect, methyl transfer to the $\mathrm{N}$-terminal half of the Ada protein causes activation of this protein, as a transcriptional regulator, thereby overproducing Ada protein and related enzymes in response to externally administered alkylating agents (for review, Sekiguchi and Nakabeppu, 1987; Lindahl et al., 1988).

The amino acid sequence of the Ogt protein has a striking homology with the $\mathrm{C}$-terminal region of the Ada protein. The Ogt protein repairs $O^{6}$-methylguanine and $O^{4}$-methylthymine and thus is structually and functionally similar to the C-terminal half of the Ada protein. Eukaryotic cells contain a single type of methyltransferase, which is similar to the $E$. coli Ogt protein. As amounts of Ogt-type proteins are not increased after treatment with alkylating agents, these proteins are regarded as constitutive enzymes.

Cloning of cDNA for human methyltransferase was achieved in 1990 by three groups of investigators, each using different strategies (Hayakawa et al., 1990; Rydberg et al., 1990; Tano et al., 1990). The amino acid sequence of the purified protein was in complete agreement with that deduced from the nucleotide sequence of the cloned cDNA (Koike et al, 1990). Using a probe derived from the human sequence, cDNAs for mouse, rat, rabbit and hamster enzymes have been isolated (Sakumi et al., 1991; Potter et al., 1991; Rahden-Staron and Laval, 1991; Shiraishi et al., 1992; Shiota et al., 1992; Rafferty et al., 1992; Iyama et al., 1994). The nucleotide sequences of the cDNAs revealed a high homology over the protein as a whole and sizes of the mammalian enzymes are slightly larger than size of the E. coli Ogt protein (Fig. 1).

Inspection of these sequences revealed that the cysteine residue accepting a methyl group from the methylated bases of DNA is located within the sequence of Pro-Cys-His-Arg (see Fig. 1). To elucidate the significance of a highly conserved amino acid sequence of the methyltransferase protein, amino acid substitutions were introduced by site-directed mutagenesis of cloned cDNA for human methyltransferase (Chueh et al., 1992). More extensive analyses were made with the $E$. coli Ogt protein, and evidence was obtained to show that the sequence Pro-CysHis-Arg is a sine qua non for methyltransferase to exert its function (Ihara et al., 1994).

\section{Functions of Methyltransferase in Preventing Mutation}

E. coli mutant strains that lack either one or both of the $a d a$ and ogt genes

Vol. 42, No. 3, 1997 


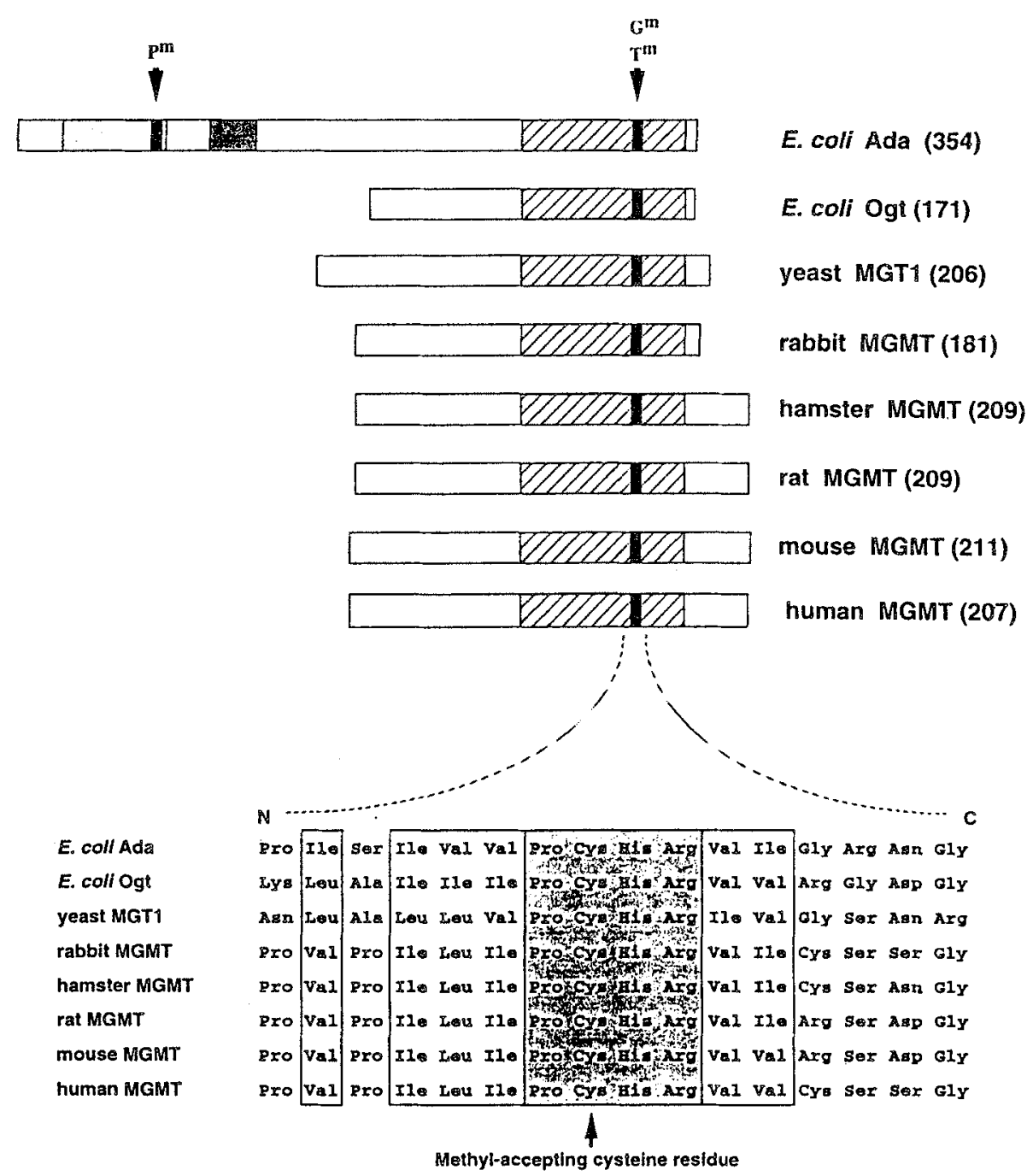

Fig. 1. Comparison of structures of DNA repair methyltransferases from various organisms. The upper panel shows the overall structures with methyl acceptor sites. Numbers in parenthesis indicate the numbers of amino acid residues of the proteins. The lower panel indicates amino acid sequences around the methyl acceptor sites.

were constructed (Takano et al., 1991). In either the $a d a^{+}$or $a d a^{-}$background, the ogt mutation had no effect on cell survival after $N$-methyl- $N^{\prime}$-nitro- $N$-nitrosoguanidine (MNNG) treatment. On the other hand, $a d a^{-}$ogt- cells were more prone to mutation as compared to the $a d a^{-}$ogt $t^{+}$cells exposed to MNNG. Although the frequency of spontaneous mutation of cells defective in either one or 
both of the genes was the same, introduction of the $o g t^{+}$plasmid into the cells produced a 2 to 3-fold decrease in the frequency of spontaneous mutation. Rebeck and Samson (1991) found that more mutations arise in non-dividing ada ${ }^{-}$ogt $^{-}$ cells than in wild type cells. Thus, methyltransferase appears to function so as to eliminate pre-mutagenic DNA lesions not only from cells exposed to alkylating agents but also from cells proliferating in the absence of these agents.

Types of mutations occurring in cells exposed to MNNG have been analyzed, using an assay for forward mutations arising in a specific gene sequence (Ito et al., 1994). Mutations recovered from wildtype strains were predominantly $G \cdot C$ to $A \cdot T$ transitions, located at several "hot" spots in the target gene. Although ada" ogt" cells showed hypersensitivity to the alkylating agent in terms of mutagenic and cell-killing effects, the type and site distribution of the mutations recovered from the mutants were similar to those observed with the wild type cells.

Some tumor-derived cell lines are hypersensitive to alkylating agents and are unable to reactivate virus pre-exposed to alkylating agents (Day et al., 1980; Sklar and Strauss, 1981; Yarosh et al., 1983). These $\mathrm{Mer}^{-}\left(\mathrm{Mex}^{-}\right)$cells have little or no methyltransferase activity, but the molecular mechanisms underlying this $\mathrm{Mer}^{-}$ character are not fully understood. No or only a little mRNA for methyltransferase was detected in $\mathrm{Mer}^{-}$cells, though there is no gross difference in coding and promoter regions of the methyltransferase gene in $\mathrm{Mer}^{+}$and $\mathrm{Mer}^{-}$cells (Pieper et al., 1990; Tano et al., 1990; Rydberg et al., 1990; Nakatsu et al., 1993). It can, therefore, be assumed that these $\mathrm{Mer}^{-}$cells are defective in transcriptional control, and this leads to the question of whether or not $\mathrm{Mer}^{-}$cells have altered expressions in genes other than that for methyltransferase itself.

For elucidation, cell lines defective particularly in the methyltransferase gene were developed, using gene targeting techniques. The cell lines have a sequence alteration in the defined region of the $M G M T$ alleles and are totally devoid of methyltransferase protein, as confirmed in immunological and enzymatic assays (Tominaga et al., 1997). $M G M T^{-1-}$ cells showed an increased mutation frequency as compared with the parental $M G M T^{+1+}$ cells when treated with a low level of MNNG (Fig. 2). This assay was made by scoring 6-thioguanine-resistant colonies which arose by forward mutations in the HPRT locus. The level of mutability of $M G M T^{-1-}$ cells was much the same as that obtained with $\mathrm{Mer}^{-}$cells, whose forward mutation frequency was measured using the same genetic marker (Domoradzki et al., 1984).

Decreased colony-forming ability of cells after exposure to alkylating agents is another notable feature of $\mathrm{Mer}^{-}$cells (Day et al., 1980). The $\mathrm{LD}_{37}$ of $M G M T^{+/+}$, $M G M T^{+1-}$ and $M G M T^{-1-}$ cells was $11.3,7.3$ and $0.11 \mu \mathrm{M}$ MNNG, respectively, and similar degrees of sensitivity were obtained with MNU (Tominaga et al., 1997). Thus, cells which are totally deficient in methyltransferase protein are 100 times more sensitive to alkylating agents than are methyltransferase-proficient cells, and this coincides with the sensitivity levels of $\mathrm{Mer}^{+}$and $\mathrm{Mer}^{-}$cells (Domor- 


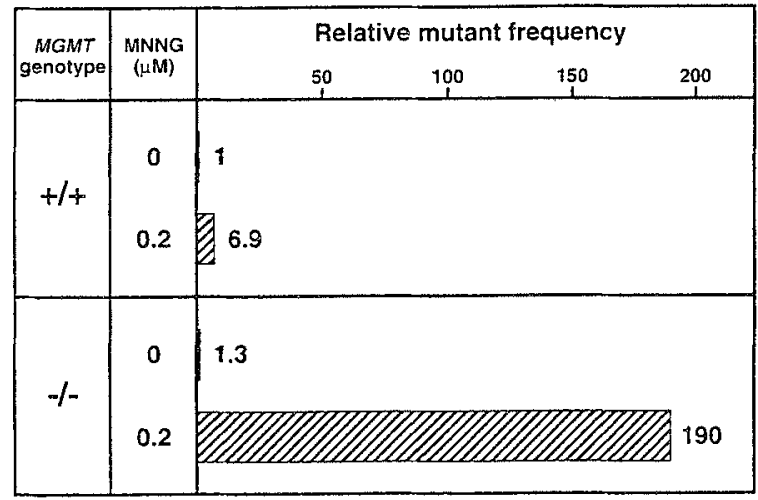

Fig. 2. Relative frequency of 6-thioguanine-resistant mutants in $M G M T^{+1+}$ and $M G M T^{-1-}$ cells after treatment with MNNG. Data were taken from Tominaga et al. (1997).

adzki et al., 1984). We found that a single cell with a $M G M T^{+1-}$ background carries $1.7 \times 10^{4}$ methyltransferase molecules, while a $M G M T^{+1+}$ cell contains $2.4 \times$ $10^{4}$ methyltransferase molecules. This enzyme level in $M G M T^{+1-}$ cells $(70 \%$ of $M G M T^{+1+}$ cell) clearly reflects the level of sensitivity of the heterozygous cell $(65 \%$ of $M G M T^{+1+}$ cell), as expected from the finding that stoichiometric amounts of methyltransferase protein are needed for DNA repair (Olsson and Lindahl, 1980).

Lowered survival of methyltransferase-deficient cell lines after treatment with alkylating agents implies that $O^{6}$-methylguanine and, to a lesser extent, $O^{4}$-methylthymine are not only mutagenic but are also lethal. The toxicity of such lesions might be attributed to the inappropriate processing of mismatch repair. This was first suggested in studies with $E$. coli dam $^{-}$strains, in which mutations in the mismatch recognition genes $m u t S$ and $m u t L$ confer protection against the toxicity of MNNG (Jones and Wagner, 1981; Karran and Marinus, 1982). Involvement of alkylated bases in mammalian cell lethality was deduced from the observation that nicks persisted in DNA of the $\mathrm{Mer}^{-}$cells that had been exposed to alkylating agents (Kalamegham et al., 1988). Recent studies indicated that an acquired resistance (methylation tolerance) of $\mathrm{Mer}^{-}$cell lines is indeed associated with loss of capacity for mismatch repair (Branch et al., 1993; Kat et al., 1993). It has been proposed that the accumulation of alkylated bases in chromosomal DNA may provoke abortive mismatch repair, thereby leading to cell death. If a defect in the mismatch gene could be introduced into $M G M T^{-1-}$ cells, then one would have a pertinent tool for examining the cause of alkylation-induced cell death.

\section{Tumorigenesis in Methyltransferase Gene-Disrupted Mice}

To elucidate the roles of methyltransferase in carcinogenesis, appropriate animal models with altered levels of the enzyme activity are needed. This can be 
achieved in two ways, one to generate transgenic mice carrying extra copies of the foreign methyltransferase gene with functional promoters and the other to produce methyltransferase-deficient mice by means of gene targeting. The latter is technically more difficult but would be more definitive regarding in vivo functions of the enzyme. We used both approaches chronologically in this order.

Transgenic mice were first generated by introducing the $E$. coli ada gene attached to the Chinese hamster metallothionein I gene promoter into mouse zygotes (Matsukuma et al., 1989). Liver extracts from these transgenic mice carry about three times the activity of normal mice and levels can be increased up to about eight times after treatment of zinc, due to the metal-responsive promoter element (Nakatsuru et al., 1991). Groups of transgenic and non-transgenic mice were given an i.p. injection of $\mathrm{ZnSO}_{4}$, and $10 \mathrm{hr}$ thereafter were given an i.p. injection of either dimethylnitrosamine or diethylnitrosamine. There was a statistically significant reduction in liver tumor formation in transgenic mice of four of the six paired groups treated, and in the remaining two results were in line with dose dependence (Nakatsuru et al., 1993). Transgenic mice expressing the ada chimeric gene or the human methyltransferase cDNA were also developed (Lim et al., 1990; Fan et al., 1990; Dumenco et al., 1991) and, in this case, an apparent reduction in rate of induction of thymic lymphoma by MNU was observed (Dumenco et al., 1993). Thus, methyltransferase can indeed protect animals from exposure to relatively low doses of alkylating carcinogenes.

In these transgenic mice, the suppressive effects on tumor formation were evident only when relatively high doses of alkylating agents were used. Moreover, as levels of expression of the transgenes vary with tissues, it can be difficult to define the protective effects of the enzyme. One would need to construct mice defective in their own methyltransferase genes. For this, elucidation of the genomic sequence for mouse methyltransferase is necessary, and so it was done (Shiraishi et al., 1992; Iwakuma et al., 1996).

Mouse lines deficient in the methyltransferase gene were established by gene targeting (Tsuzuki et al., 1996). Tissues from these mice contained essentially no methyltransferase protein. Administration of $\mathrm{MNU}(50 \mathrm{mg} / \mathrm{kg}$ of body weight) to these gene-targeted mice led to early death whereas normal mice treated in the same manner showed no untoward effects. In methyltransferase-deficient mice given MNU treatment, the bone marrow became hypocellular and there was a drastic decrease in the number of leukocytes and platelets in peripheral blood, thereby indicating an impaired reproductive capacity of hematopoietic stem cells. Methyltransferase apparently protected these mice from the pancytopenia caused by the alkylating agent.

When varied doses of MNU were administered to 6-week-old mice and the survivors on the 30 th day were counted, $\mathrm{LD}_{50}$ of $M G M T^{-1-}$ and $M G M T^{+1+}$ mice was 20 and $240 \mathrm{mg} / \mathrm{kg}$ of body weight, respectively (Fig. 3). Then, a sublethal dose of MNU $(2.5 \mathrm{mg} / \mathrm{kg}$ of body weight, as shown by an arrow in the figure) was

Vol. 42, No. 3, 1997 


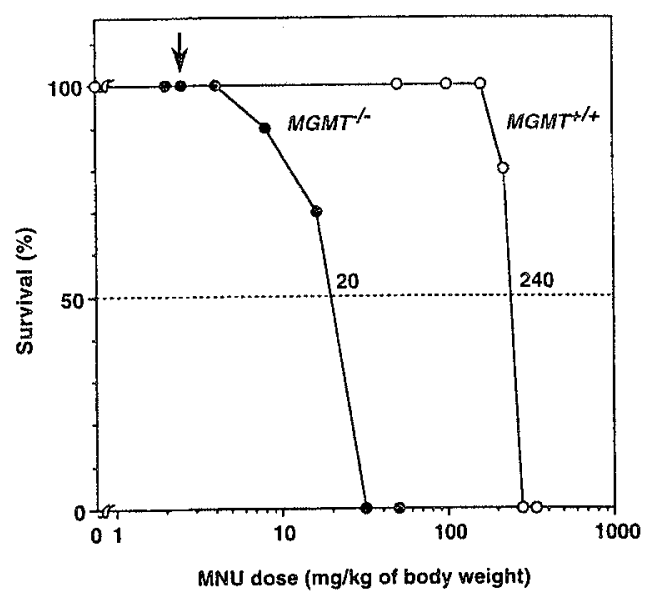

Fig. 3. Survival of $M G M T^{+1+}$ and $M G M T^{-1-}$ mice given different doses of MNU. Survival rates at the 30 th day after MNU injection were plotted. Data were taken from Sakumi et al. (1997).

applied and the animals were observed for 28 weeks. Thymic lymphoma and lung adenoma were present in many of $M G M T^{-1-}$ mice while there was only one lung adenoma in the $M G M T^{+/+}$mice (Sakumi et al., 1997). In $M G M T^{-1-}$ female mice given an i.p. injection of dimethylnitrosamine $(5 \mathrm{mg} / \mathrm{kg})$, a significantly larger number of liver and lung tumors were produced, as compared with $M G M T^{+/+}$ mice treated in the same manner (Iwakuma et al., 1997). Thus, it is clear that mice with a defect in the $M G M T$ gene are indeed susceptible to alkylation-induced tumorigenesis.

It has been proposed that the accumulation of alkylated bases in chromosomal DNA may provoke abortive mismatch repair, thereby leading to cell death (Branch et al., 1993; Kat et al., 1993). It is now possible to test this hypothesis by constructing mice defective in both methyltransferase and mismatch repair genes. By making use of methyltransferase-deficient mice, one could also evaluate the extent of an endogenous alkylation-induced DNA lesion that would lead to induction of mutation as well as to cancer.

Acknowledgments We thanks Drs. T. Tsuzuki, H. Hayakawa and Y. Nakabeppu for discussion, and M. Ohara for comments on the manuscript. This work was supported by Grants-in-Aid from the Ministry of Education, Science, Sports and Culture of Japan and by a research grant from the Uehara Foundation.

\section{REFERENCES}

Branch P, Aquilina G, Bignami M, Karran P (1993): Defective mismatch binding and a mutator phenotype in cells tolerant to DNA damage. Nature 362: 652-654

Chueh LL, Nakamura T, Nakatsu Y, Sakumi K, Hayakawa H, Sekiguchi M (1992): Specific 
amino acid sequences required for $O^{6}$-methylguanine-DNA methyltransferase activity: analyses of three residues at or near the methyl acceptor site. Carcinogenesis 13: 837-843

Coulondre C, Miller JH (1977): Genetic studies of the lac repressor IV. Mutagenic specificity in the lacI gene of Escherichia coli. J Mol Biol 117: 577-606

Day RS III, Ziolkowski CHJ, Scudiero DA, Meyer SA, Mattern MR (1980): Human tumor cell strains defective in the repair of alkylation damage. Carcinogenesis 1: 21-32

Demple B, Jacobsson A, Olsson M, Robins P, Lindahl T (1982): Repair of alkylated DNA in Escherichia coli: physical properties of $O^{6}$-methylguanine-DNA methyltransferase. J Biol Chem 257: 13776-13780

Demple B, Sedgwick B, Robins P, Totty N, Waterfield MD, Lindahl T (1985): Active site and complete sequence of the suicidal methyltransferase that counters alkylation mutagenesis. Proc Natl Acad Sci USA 82: 2688-2692

Domoradzki J, Pegg AE, Dolan ME, Maker VM, McComick JJ (1984): Correlation between $O^{6}$-methylguanine-DNA methyltransferase activity and resistance of human cells to the cytotoxic and mutagenic effect of $N$-methyl- $N^{\prime}$-nitro- $N$-nitrosoguanidine. Carcinogenesis 5 : 1641-1647

Dumenco LL, Arce C, Norton K, Yun J, Wagner T, Gerson SL (1991): Enhanced repair of $O^{6}$-methylguanine DNA adducts in the liver of transgenic mice expressing the ada gene. Cancer Res 51: 3391-3398

Dumenco LL, Allay E, Norton K, Gerson SL (1993): The prevention of thymic lymphoma in transgenic mice by human $O^{6}$-alkylguanine-DNA alkyltransferase. Science 259: 219-222

Fan CY, Potter PM, Rafferty J, Watson AJ, Cawkwell L, Searle PF, O'Conner PJ, Margison GP (1990): Expression of a human $O^{6}$-alkylguanine-DNA alkyltransferase cDNA in human cells and transgenic mice. Nucleic Acids Res 18: 5723-5727

Gerson SL, Trey JE, Miller K, Berger NA (1986): Comparison of $O^{6}$-alkylguanine-DNA alkyltransferase activity based on cellular DNA content in human, rat and mouse tissues. Carcinogenesis 7: 745-749

Goth R, Rajewsky MF (19.74): Persistence of $O^{6}$-ethylguanine in rat brain DNA: correlation with nervous system-specific carcinogenesis by ethylnitrosourea. Proc Natl Acad Sci USA 71: 639 643

Hayakawa H, Koike G, Sekiguchi M (1990): Expression and cloning of complementary DNA for a human enzyme that repairs $O^{6}$-methylguanine in DNA. J Mol Biol 213: 739-747

Ihara K, Kawate H, Chueh LL, Hayakawa H, Sekiguchi M (1994): Requirement of the Pro-CysHis-Arg sequence for $O^{6}$-methylguanine-DNA methyltransferase activity revealed by saturation mutagenesis with negative and positive screening. Mol Gen Genet 243: 379-389

Ishibashi T, Nakabeppu Y, Kawate H, Sakumi K, Hayakawa H, Sekiguchi M (1994a): Intracellular localization and function of DNA repair methyltransferase in human cells. Mutat Res 315: $199-212$

Ishibashi T, Nakabeppu Y, Sekiguchi M (1994b): Artificial control of nuclear translocation of DNA repair methyltransferase. J Biol Chem 269: 7645-7650

Ito T, Nakamura T, Maki H, Sekiguchi M (1994): Roles of transcription and repair in alkylation mutagenesis. Mutat Res 314: 273-285

Iwakuma T, Shiraishi A, Fukuhara M, Kawate H, Sekiguchi M (1996): Organization and expression of the mouse gene for DNA repair methyltransferase. DNA Cell Biol 15: 863-872

Iwakuma T, Sakumi K, Nakatsuru Y, Kawate H, Igarashi H, Shiraishi A, Tsuzuki T, Ishikawa T, Sekiguchi M (1997): High incidence of nitrosamine-induced tumorigenesis in mice lacking DNA repair methyltransferase. Carcinogenesis 18: 1631-1635

Iyama A, Sakumi K, Nakabeppu Y, Sekiguchi M (1994): A unique structural feature of rabbit DNA repair methyltransferase as revealed by cDNA cloning. Carcinogenesis 15: 627-633

Jones M, Wagner R (1981): $N$-Methyl- $N^{\prime}$-nitro- $N$-nitrosoguanidine sensitivity of $E$. coli mutants deficient in DNA methylation and mismatch repair. Mol Gen Genet 184: 562-563

Kalamegham R, Warmels RS, MacDonald H, Ebisuzaki K (1988): $O^{6}$-Methylguanine-DNA methyltransferase-defective human cell mutant: $O^{6}$-methylguanine, DNA strand breaks and

Vol. 42, No. 3, 1997 
cytotoxicity. Carcinogenesis 9: 1749-1753

Karran P, Marinus MG (1982): Mismatch correction at $O^{6}$-methylguanine residues in $E$. coli DNA. Nature 296: 868-869

Kat A, Thilly WG, Fang WH, Longley MJ, Li GM, Modrich P (1993): An alkylation-tolerant, mutator human cell line is deficient in strand-specific mismatch repair. Proc Natl Acad Sci USA 90: 6424-6428

Kleihues P, Margison GP (1974): Carcinogenicity of $N$-methyl- $N$-nitrosourea: possible role of excision repair of $O^{6}$-methylguanine from DNA. J Natl Cancer Inst 53: 1839-1841

Koike G, Maki H, Takeya H, Hayakawa H, Sekiguchi Mi (1990): Purification, structure and biochemical properties of human $O^{6}$-methylguanine-DNA methyltransferase. $J$ Biol Chem 265: $14754-14762$

LeMotte PK, Walker GC (1985): Induction and autoregulation of ada, a positively acting element regulating the response of Escherichia coli K-12 to methylating agents. $\mathrm{J}$ Bacteriol 161: $888-895$

Lim IK, Dumenco LL, Yun J, Donovan C, Warman B, Gorodetzkaya N, Wagner TE, Clapp DW, Hanson RW, Gerson SL (1990): High level, regulated expression of the chimeric P. enolpyruvate carboxykinase (GTP)-bacterial $O^{6}$-alkylguanine-DNA alkyltransferase $(a d a)$ gene in transgenic mice. Cancer Res 50: 1701-1708

Lindahl T, Sedgwick B, Sekiguchi M, Nakabeppu Y (1988): Regulation and expression of the adaptive response to alkylating agents. Annu Rev Biochem 57: 133-157

Loveless A (1969): Possible relevance of $O^{6}$ alkylation of deoxyguanosine to the mutagenicity and carcinogenicity of nitrosamines and nitrosamides. Nature 223: 206-207

Margison GP, Cooper DP, Brennand J (1985): Cloning of the $E$. coli $O^{6}$-methylguanine and methylphosphotriester methyltransferase gene using a functional DNA repair assay. Nucleic Acids Res 13: 1939-1952

Matsukuma S, Nakatsuru Y, Nakagawa K, Utakoji T, Sugano H, Kataoka H, Sekiguchi M, Ishikawa T (1989): Enhanced $O^{6}$-methylguanine-DNA methyltransferase activity in transgenic mice containing an integrated $E$. coli ada repair gene. Mutat Res 218: 197-206

Nakabeppu Y, Kondo H, Kawabata S, Iwanaga S, Sekiguchi M (1985): Purification and structure of the intact Ada regulatory protein of Escherichia coli $\mathrm{K} 12, O^{6}$-methylguanine-DNA methyltransferase. J Biol Chem 260: 7281-7288

Nakatsu Y, Hattori K, Hayakawa H, Shimizu K, Sekiguchi M (1993): Organization and expression of the human gene for $O^{6}$-methylguanine-DNA methyltransferase. Mutat Res 293: 119 132

Nakatsuru Y, Matsukuma S, Nemoto N, Sugano H, Sekiguchi M, Ishikawa T (1993): $O^{6}$-Methylguanine-DNA methyltransferase protects against nitrosamine-induced hepatocarcinogenesis. Proc Natl Acad Sci USA 90: 6468-6472

Nakatsuru Y, Matsukuma S, Sekiguchi M, Ishikawa T (1991): Characterization of $O^{6}$-methylguanine-DNA methyltransferase in transgenic mice introduced with the $E$. coli ada gene. Mutat Res 254: 225-230

Olsson M, Lindahl T (1980): Repair of alkylated DNA in Escherichia coli: Methyl group transfer from $O^{6}$-methylguanine to a protein cysteine residue. J Biol Chem 255: 10569-10571

Pieper RO, Futscher BW, Dong Q, Ellis TM, Erickson LC (1990): Comparison of O-6-methylguanine DNA methyltransferase (MGMT) mRNA levels in $\mathrm{Mer}^{+}$and $\mathrm{Mer}^{-}$human tumor cell lines containing the MGMT gene by the polymerase chain reaction technique. Cancer Commun 2: 13-20

Potter PM, Rafferty JA, Cawkwell L, Wilkinson MC, Cooper DP, O'Connor PJ, Margison GP (1991): Isolation and cDNA cloning of a rat $O^{6}$-alkylguanine-DNA alkyltransferase gene, molecular analysis of expression in rat liver. Carcinogenesis 12: 727-733

Rafferty JA, Elder RH, Watson AJ, Cawkwell L, Potter PM, Margison GP (1992): Isolation and partial characterization of a Chinese hamster $O^{6}$-alkylguanine-DNA alkyltransferase cDNA. Nucleic Acids Res 20: 1891-1895

Rahden-Staron I, Laval F (1991): cDNA cloning of the rat $O^{6}$-methylguanine-DNA methyltrans- 
ferase. Biochern Biophys Res Commun 177: 597-602

Rebeck GW, Samson L (1991): Increased spontaneous mutation and alkylation sensitivity of Escherichia coli strains lacking the ogt $O^{6}$-methylguanine DNA repair methyltransferase. J Bacteriol 173: 2068-2076

Rydberg B, Spurr N, Karran P (1990): cDNA cloning and chromosomal assignment of the human $O^{6}$-methylguanine-DNA methyltransferase: cDNA expression in Escherichia coli and gene expression in human cells. J Biol Chem 265: 9563-9569

Sakumi K, Shiraishi A, Hayakawa H, Sekiguchi M (1991): Cloning and expression of cDNA for rat $O^{6}$-methylguanine-DNA methyitransferase. Nucleic Acids Res 19: 5597-5601

Sakumi K, Shiraishi A, Shimizu S, Tsuzuki T, Ishikawa T, Sekiguchi M (1997): Methylnitrosourea-induced tumorigenesis in $M G M T$ gene knockout mice. Cancer Res 57: 2415-2418

Sekiguchi M, Nakabeppu Y (1987): Adaptive response: induced synthesis of DNA repair enzymes by alkylating agents. Trends Genet 3: 51-54

Sekiguchi M, Nakabeppu Y, Sakumi K, Tsuzuki T (1996): DNA-repair methyltransferase as a molecular device for preventing mutation and cancer. J Cancer Res Clin Oncol 122: 199-206

Shiota S, von Wronski MA, Tano K, Bigner DD, Brent TP, Mitra S (1992): Characterization of cDNA encoding mouse DNA repair protein $O^{6}$-methylguanine-DNA methyltransferase and high level expression of the wild-type and mutant proteins in Escherichia coli. Biochemistry 31: $1897-1903$

Shiraishi A, Sakumi K, Nakatsu Y, Hayakawa H, Sekiguchi M (1992): Isolation and characterization of cDNA and genomic sequences for mouse $O^{6}$-methylguanine-DNA methyltransferase. Carcinogenesis 13: 289-296

Sklar R, Strauss B (1981): Removal of $O^{6}$-methylguanine from DNA of normal and xeroderma pigmentosum-derived lymphoblastoid lines. Nature 289: 417-420

Strauss B, Scudiero D, Henderson E (1975): The nature of the alkylation lesion in mammalian cells. In: Hanawalt PC, Setlow RB (eds). Molecular mechanisms for repair of DNA. Plenum, New York, Part A, pp 13-24

Sukumar S, Notario V, Martin-Zanca D, Barbacid M (1983): Induction of mammary carcinomas in rats by nitroso-methylurea involves malignant activation of $\mathrm{H}$-ras-1 locus by single point mutations. Nature 306: 658-661

Takano K, Nakamura T, Sekiguchi M (1991): Roles of two types of $O^{6}$-methylguanine-DNA methyltransferase in DNA repair. Mutat Res 254: 37-44

Tano K, Shiota S, Collier J, Foote RS, Mitra S (1990): Isolation and structural characterization of a cDNA clone encoding the human DNA repair protein for $O^{6}$-alkylguanine. Proc Natl Acad Sci USA 87: 686-690

Tominaga Y, Tsuzuki T, Shiraishi A, Kawate H, Sekiguchi M (1997): Alkylation-induced apoptosis of embryonic stem cells in which the gene for DNA repair, methyltransferase, had been disrupted by gene targeting. Carcinogenesis 18: 889-896

Tsuzuki T, Sakumi K, Shiraishi A, Kawate H, Igarashi H, Iwakuma T, Tominaga Y, Zhang S, Shimizu S, Ishikawa T, Nakamura K, Nakao K, Katsuki M, Sekiguchi M (1996): Targeted disruption of the DNA repair methyltransferase gene renders mice hypersensitive to alkylating agent. Carcinogenesis 17: 1215-1220

Wilkinson MC, Potter PM, Cawkwell L, Georgiadis P, Patel D, Swann PF, Margison GP (1989): Purification of the $E$. coli ogt gene product to homogeneity and its rate of action of $O^{6}$-methylguanine, $O^{6}$-ethylguanine and $O^{4}$-methylthymine in dodecadeoxyribonucleotides. Nucleic Acids Res 17: 8475-8484

Yarosh DB, Foote RS, Mitra S, Day RS III (1983): Repair of $O^{6}$-methylguanine in DNA by demethylation is lacking in $\mathrm{Mer}^{-}$human tumor cell strains. Carcinogenesis 4: 199-205

Zaidi NH, Pretlow TP, O'Riordan MA, Dumenco LL, Allay E, Gerson SL (1995): Transgenic expression of human MGMT protects against azoxymethane-induced aberrant crypt foci and $\mathrm{G}$ to A mutations in the K-ras oncogene of mouse colon. Carcinogenesis 16: 451-456 